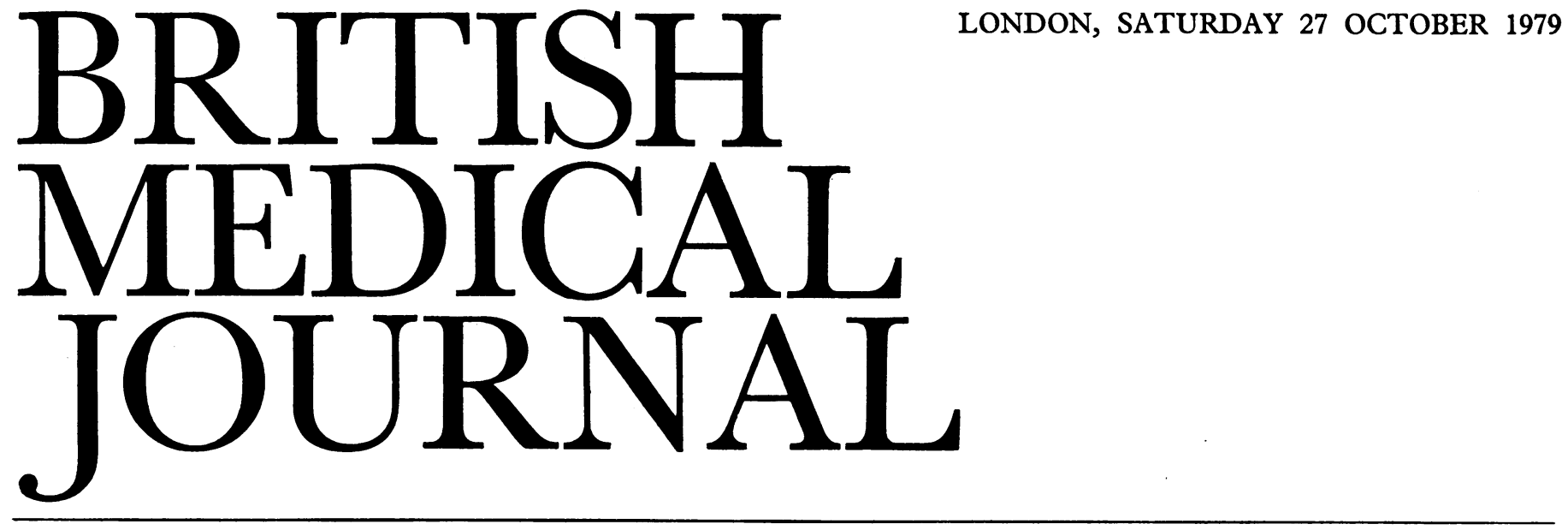

\title{
Fibrinolytic therapy in myocardial infarction
}

Throughout recorded medical history liquid blood has been known to turn into a solid coagulum when shed from the body or examined in the blood vessels after death. Not until the eighteenth century, however, did observers recognise that blood remains incoagulable in violent death or death after strenuous exercise. During the next century this incoagulability was shown to be due to the activation of a complex enzyme system which could digest fibrin. Finally, in the twentieth century, the fibrinolytic system was found to be capable of being triggered in a controlled fashion by activators produced by haemolytic streptococci (streptokinase) or present in human urine (urokinase). ${ }^{1}$

Formation of a thrombus depends in part on processes such as platelet deposition, which may not be directly related to blood coagulation. ${ }^{2}$ Nevertheless, a substantial part of the bulk of a thrombus, especially in the venous system, is contributed by a fibrin meshwork, so it was natural to speculate whether the administration of activators of the fibrinolytic system would modify the outcome of thrombotic disease. In a condition such as myocardial infarction, the clinical outcome may not be influenced by subsequent thrombolysis if sinister irreversible events have already happened by the time the patient presents. Thus the extent or siting of an infarcted area of myocardium may have already marked the victim out for death from ventricular fibrillation or pump failure, when the removal of the thrombus would be irrelevant. On the other hand, lysis of the thrombus might be able to ensure early reperfusion of a twilight zone of ischaemic but viable tissue, or might prevent extension of the initial thrombus and the formation of new thrombi, thereby improving prognosis. The only way to determine the validity of these concepts is by clinical trials.

In the early 1960s, pilot studies showed that lytic treatment could be used safely in patients with acute myocardial infarction. ${ }^{3}$ During the next 10 years the results of a series of large-scale clinical trials ${ }^{4}$ suggested that mortality could be reduced by the early administration of streptokinase. This early optimism was, however, short lived; later controlled trials showed no significant benefit from streptokinase ${ }^{4}$ or urokinase. $^{5}$ Nevertheless, in the interval between the early favourable trials and the later negative ones the management of patients with myocardial infarction had altered substantially, from care in ordinary wards with limited availability of monitoring and defibrillation to admission to specialised coronary or intensive care units. Might the lower mortality prevailing in the later trials be obscuring a real benefit from lytic therapy in certain subgroups of patients with infarcts?

In an attempt to answer that question the European Cooperative Study Group organised another multicentre study of the effect of streptokinase in acute infarction, and the findings were published last week in the New England fournal of Medicine. ${ }^{6}$ A total of 2338 patients with suspected infarction were seen in the participating centres during the study period; only 315 of these $(13.5 \%$ of the total) were entered into the randomly allocated study: all subsequently took coumarin anticoagulants for at least three weeks. Entry to the trial had to be within the first 12 hours of the onset of chest pain. During that period changes in the concentration of the cardiac enzymes will not necessarily have achieved their full diagnostic potential, and yet enzyme concentrations were one of the inclusion criteria. The patients were followed for six months, at which time 48 control patients and 24 patients treated with streptokinase had died. The striking thing about this highly significant difference is that the main divergence in outcome occurred after the acute episode: at 21 days there had been 28 control and 18 streptokinase deaths, whereas between 21 days and six months 20 more patients in the control group died compared with only six of the streptokinasetreated group. The obvious question to ask is how can infusion of a lytic agent for the first 24 hours after admission influence late mortality in this way?

Close analysis of the report shows that the two groups were not comparable in all respects other than the treatment under scrutiny: in the streptokinase group fewer patients had previously had infarcts or developed dysrhythmias in the coronary care unit. While random allocation gave patients an equal chance of entering the two treatment groups, it failed to balance out all the highly relevant risk factors.

If, however, the differences in outcome were real and did not simply reflect the differences between the two groups in respect of various risk factors, what explanation can we offer? Some tantalising haemodynamic pointers emerge: firstly, systolic blood pressures fell more markedly in the patients treated with streptokinase. This could produce benefit by reducing cardiac work load, and the study group speculates that the fall may be due to a reduction in blood viscosity by the lytic process. Secondly, pulmonary artery pressures were lower in the treated group; in view of the proved efficacy of 
streptokinase in clearing pulmonary emboli, it is surprising that the group do not discuss the possibility that an effect on venous thromboembolism might account for their haemodynamic findings and for part of the favourable effect on mortality. Finally, there was a definite and inexplicable difference in the size of the heart at six months between the groups, fewer of the patients given lytic treatment having enlargement of the heart.

The study group is to be commended for its ability to mount such a trial, but the low randomisation rate, the uncertainty about the comparability of the two groups, and the clinical and laboratory complexities inherent in any effective and well-controlled lytic regimen will limit the practical impact of the study on doctors caring for patients with acute infarction. If, however, the mechanisms which underlie the apparent effect of streptokinase on mortalityand especially on late mortality-can be discovered and can be produced by less demanding regimens, then a real advance will have been made.

1 Fearnley, G R, Fibrinolysis. London, Arnold, 1965.

2 Mitchell, J R A, in Advanced Medicine, 14th edn, ed D J Weatherall, p 228. Tunbridge Wells, Pitman Medical, 1978.

3 Dewar, H A, Horler, A R, and Cassells-Smith, A J, British Medical fournal, 1961, 2, 671 .

4 Fratantoni, J C, Ness, P, and Simon, T L, New England fournal of Medicine, 1975, 293, 1073.

5 European Collaborative Study, Lancet, 1975, 2, 624.

${ }^{6}$ European Cooperative Study Group for Streptokinase Treatment in Acute Myocardial Infarction, New England fournal of Medicine, 1979, 301, 797.

\section{Privacy, epidemiology, and record linkage}

The vast publicity given to the unexpected and serious side effects of practolol testified to the extent of public interest in toxicity from drugs as well as industrial chemicals. That incident also showed that, despite exhaustive tests in animals and a national reporting system, a serious adverse effect to a new drug may occur on a substantial scale before it is recognised. Indeed, extrapolation from in vitro tests and animal studies to man seems likely always to be fallible. Nor, with the present body of theoretical knowledge, can we accurately predict the occurrence and incidence of toxic effects in man to a given chemical. For the foreseeable future, the best safeguard will be the collection of reliable data on exposure to chemical agents of all kinds and illness in man.

This implies record systems that make possible the linkage of information into personal cumulative files-because records on exposure and on illness are often widely separated in time and usually stored in different places. The creation of such files often meets with vigorous opposition on the grounds that the individuals concerned have not consented to the use of information about them for this purpose, or that the existence of such files may place unacceptable power and opportunity for abuse in the hands of the custodian-particularly if this should be a government department.

The National Cancer Institute of Canada recently sponsored a workshop to mark the retirement of $\mathrm{H} \mathrm{B}$ Newcombe, the originator of an ingenious and effective method of linking personal records by computer. In Canada a computer-based index of deaths for the last 27 years is available (under stringent safeguards for privacy) for linkage with data about exposure of individuals to various agents. The workshop was shown preliminary results of the use of this file. A hypothesis that isoniazid is not carcinogenic was tested by linking the files of 64000 people treated for tuberculosis since 1952 with the mortality data, and the scope of the system for environmental monitoring was shown by extracting and linking the occupational records of a $10 \%$ sample of the Canadian work force. In the United States a computer-based index of about 20 million deaths each year will be available for epidemiological research from the beginning of 1980 .

What of the fears about privacy? One outstanding feature of the workshop was its session on this theme, with contributions from a judge of the Supreme Court of Ontario, a trade union official, and a civil servant. Though there were differences in emphasis, all the participants thought that rigorous safeguards for privacy could be provided without putting epidemiological research in chains. A contributor from the United States said that pressure was growing in Congress to remove some of the obstacles that the Privacy Act of 1974 had placed in the way of the solution of environmental health problems by epidemiological means.

Here in Britain H B Newcombe's method of record linkage has been applied successfully for many years in the Oxford Record Linkage Study and in Scotland. The Office of Population Censuses and Surveys uses a manual method of record linkage in its $1 \%$ longitudinal study and for following cohorts of people in respect of death and the development of cancer. All are yielding useful results, though in the OPCS cancer study the sample size is too small to help much in monitoring the effects of environmental chemicals. It would be ironical if these systems-which have helped to keep Britain in the van of epidemiological research-were threatened by the current financial cuts or by a restrictive Data Protection Act, when in North America similar systems are now beginning to receive priority and satisfactory solutions to the issues of privacy may be at hand.

\section{Creeping spurge}

Not everyone will know what creeping spurge is: could it be a progressive paralysis of sheep, or perhaps a term used in Scotland for misty drizzle? In fact, it is one of the common names for Euphorbia myrsinites, a plant of Mediterranean origin which now creeps around greenhouses and rock gardens throughout the United States. When broken, its thick central stem exudes a milky latex. Children like to play with this sap and to rub it into their skin and on their toys; and in so doing they can cause some spectacular eruptions.

The reactions in a recent North American epidemic ${ }^{1}$ were so fierce that the patients turned up at a poisoning control centre rather than at a skin clinic. Alarming swellings and blistering, usually on the face, appeared from two to eight hours after exposure, and mostly cleared over the next four days. Twenty patients with reactions to spurge were seen over three years and Spoerke and Temple ${ }^{1}$ believe that many additional cases were missed through lack of familiarity with the clinical picture-but this is always a problem with plant reactions. Indeed, how many doctors (let alone members of the public and their children) are familiar with the 4000 or so species of spurges (Euphorbia spp) ? Many of these are common weeds living inconspicuously in the general greenness of the countryside. Most contain a milky sap which may be highly irritant, and this property has been used for purposes as 